\title{
Biomass and productivity are strongly affected by stand factors, while ecosystem stability is dominated by biodiversity in a tropical forest
}

\author{
Zhiwen Guo ${ }^{1}$, Xiangping Wang ${ }^{1}$, and Dayong Fan ${ }^{1}$ \\ ${ }^{1}$ Beijing Forestry University
}

May 11, 2020

\begin{abstract}
In natural forests, it is increasingly suggested that stand factors are far more important for community biomass and productivity than biodiversity, but the relative importance of stand factors vs. diversity on ecosystem stability, and how their relative roles change with grain size, still remain unclear. Using inventory data from tropical forest plots in southwestern China from 2004 to 2010, we found that stand factors were clearly more stronger drivers than diversity for forest biomass and productivity (at each grain size from $400 \mathrm{~m}^{2}$ to $0.25 \mathrm{ha}$ ), while diversity was predominate for temporal stability of biomass and productivity. The effect of diversity on biomass and productivity increased with increasing grain size, but did not change clearly for ecosystem stability. Functional diversity was more important for ecosystem functions and stability than taxonomic and phylogenetic diversity, and richness was more important than the other two diversity components (evenness and divergence). Our results reconcile the recent debate on the relative importance of diversity vs. stand factors on ecosystem properties, and suggest that forest management to adjust stand structure is an effective way to increase forest carbon storage rapidly, but biodiversity conservation may be crucial for long-term ecosystem stability under climate change.
\end{abstract}

\section{INTRODUCTION}

For decades, ecologists have realized that global change has caused rapid losses in biological diversity, which may in turn led to reductions in important ecosystem functions and services (Duffy 2009; Isbell et al. 2011; Hooper et al. 2012; Liang et al. 2016; Huang et al. 2018). The relationship between biodiversity and ecosystem functions (BEF), e.g. productivity or biomass, and their stability have thus become an important part of ecological research since the 1990s (Wardle et al. 2000; Ruijven \& Berendse 2005; Tilman et al. 2014; van der Plas 2019). Previous theoretical and experimental studies have shown that diversity has a significant effect on ecosystem functions and stability (Naeem \& Li 1997; Loreau 1998; Cadotte et al. 2012; Loreau \& de Mazancourt 2013; Pennekamp et al. 2018). While there were a number of BEF studies, however, many of them were conducted in algae, wetland or grassland ecosystems (Tilman et al. 2006; Isbellet al. 2009; de Mazancourt et al. 2013; Morin et al. 2014; Craven et al. 2018; Pennekamp et al. 2018). In natural forests, whether biodiversity is important for forest biomass and productivity is still hotly debated (Fotis et al. 2018; Ouyang et al. 2019). Moreover, knowledge on the biodiversity effect on forest ecosystem stability is still limited (Mazzochiniet al. 2019), especially in tropical forests which cover only $7^{\sim} 10 \%$ of the Earth's land surface but account for $55 \%$ of carbon pool and $70 \%$ of carbon sink in global forests, and hold $96 \%$ of the world's estimated 45,000 tree species (Panet al. 2011; Poorter et al. 2015).

Two hypotheses were commonly used to explain the effect of biodiversity on ecosystem functions. The complementarity effect hypothesis assumes that difference in niches among coexisting species lead to higher resource utilization efficiency, thereby, increasing diversity enhances ecosystem productivity through niche differentiation and facilitation (Tilman et al. 1997). Meanwhile, the sampling effect hypothesis proposes 
that higher diversity increases community productivity through an increased chance of possessing highly productive species (Hooperet al. 2005). As for the positive influence of diversity on ecosystem stability, the insurance hypothesis suggests that the asynchrony of different species responding to environmental changes ensures that ecosystem functions have a lower variability when disturbance occurs, and consequently enhances ecosystem stability (Naeem \& Li 1997; Mori et al. 2013). At the same time, the change of interactions among species with time can also enhance ecosystem stability, which reflects the niche complementary on the temporal scale (Morin et al. 2014; del Río et al. 2017; Mazzochiniet al. 2019). The niche complementary of coexisting species on temporal and spatial scales ultimately leads to lower variability of ecosystem functions in higher-diversity communities.

Earlier BEF studies generally examined the effect of taxonomic diversity (TD) on ecosystem functions, and species richness is still the most widely used metric till now (Liang et al. 2016; Huang et al. 2018). However, the necessity of including other diversity dimensions and components is increasingly recognized (Craven et al. 2018; van der Plas 2019). In addition to TD, functional diversity (FD) and phylogenetic diversity (PD) are also critical diversity dimensions, which are useful to better address the processes responsible for spatial and temporal dynamics of species co-occurrence (Jarzyna \& Jetz 2016). Some studies have shown that functional and/or phylogenetic diversity are stronger predictors than taxonomic diversity for ecosystem functions (Craven et al. 2018; Hao et al. 2018; Mazzochiniet al. 2019; Staples et al. 2019). Meanwhile, diversity still includes three components, namely richness, evenness and divergence (Mason et al. 2005; Helmus et al. 2007; Mouchetet al. 2010), with increasing studies found that evenness and divergence may also be important for ecosystem functions and stability (Zhang et al. 2012; Potter \& Woodall 2014; Shirima et al.2015). However, previous BEF studies have seldom included these diversity components and dimensions simultaneously (Flynn et al.2011; Zhang et al. 2012; Craven et al. 2018), it still remains unclear about the relative importance of the richness, evenness and divergence of species, functional and phylogenetic diversity in natural forests. It also remains unclear whether their relative roles differ between distinctive ecosystem functions, e.g. forest biomass and productivity (stock and rate, respectively; see Schmid et al. 2009), and differ between ecosystem functions and their temporal stability.

Experiments that manipulate diversity generally report a strong effect of diversity on ecosystem functions (Isbell et al. 2017; Isbellet al. 2018; van der Plas 2019). However, whether these conclusions obtained from artificial communities can be extrapolated to natural communities has long been controversial, especially for natural forests with far more complex community structure (Poorter et al.2017; van der Sande et al. 2017; Satdichanh et al. 2019). Increasing studies have shown that though diversity had a significant effect on biomass or productivity, the effect can be very weak compared to environmental gradients, species (functional) identity and stand structure (Ma et al. 2010; Wu et al. 2015a; van der Sandeet al. 2018; Ouyang et al. 2019; Staples et al.2019). For instance, two recent studies have illustrated the much stronger role of stand structure attributes over diversity in shaping forest biomass and productivity patterns, respectively in temperate (Fotis et al. 2018) and subtropical forests (Ouyang et al. 2019). While these findings still need further testing, they also raised an interesting question which has not been examined before: what are the relative roles of diversity vs. stand factors in affecting the temporal stability of forest biomass and productivity? Based on the above-mentioned hypotheses on ecosystem stability (e.g. the insurance hypothesis), and evidence from manipulation experiments (del Ríoet al. 2017; Schnabel et al. 2019), it can be predicted that diversity metrics are critical for the stability of forest productivity. However, we also can not reject the possibility that stand factors may be more important than diversity in natural forest, similar as what was found for biomass and productivity per se (Fotiset al. 2018; Ouyang et al. 2019).

Meanwhile, the relationship between diversity and ecosystem functions may change with grain size (Chisholm et al. 2013; Thompsonet al. 2018; Luo et al. 2019). Chisholm et al. (2013) found that the relationship of species richness with productivity and biomass is the strongest at a $400 \mathrm{~m}^{2}$ plot size. However, later studies suggest that the relationship is the strongest at about $1000 \mathrm{~m}^{2}$ (Thompson et al. 2018), or even larger grain size (Luo et al. 2019; Mazzochini et al.2019). Thus, the scale dependence of BEF relationships still need further examination. It is also notable that how the biodiversity effect on ecosystem stability changes with grain size has much less been examined compared with forest biomass and productivity (Wang \& Loreau 
2014), despite it is an urgent question for sustainable forest ecosystem services in the context of rapid global climate change (Mazzochini et al. 2019).

In summary, here we aimed to examine three inter-related questions as follows: 1) In tropical forests, what are the relative effects of diversity vs. stand factors on biomass/productivity, as well as ecosystem stability? 2) How does the relative importance of diversity and stand factors change with grain size? 3) Which of the three diversity components (richness, evenness and divergence) and three dimensions (taxonomic, phylogenetic and functional diversity) are more important for ecosystem functions and stability?

To examine these questions, we used a dataset from 10 permanent plots $(50 * 50 \mathrm{~m}$ each) in the tropical rainforests of Xishuangbanna (southwest China), which were revisited annually from 2004 to 2010. We also split each 0.25 ha plot into subplots with three grain sizes $\left(400,800\right.$ and $\left.1200 \mathrm{~m}^{2}\right)$ to examine the scaledependence of diversity effect on stand biomass, productivity and their stability. Based on previous studies, we tested several predictions for our questions as follows. 1) Stand factors, instead of diversity, are the main drivers of forest biomass and productivity (Gough et al. 2019; Ouyanget al. 2019). By contrast, diversity may be more important for the temporal stability of productivity and biomass (Delsol et al. 2018). 2) The complementarity and asynchrony between coexisting species is hypothesized to increase with lager grain size (Bond \& Chase 2002; Delsol et al. 2018), and thus it is predicted that the effect of diversity on ecosystem functions and stability should increase with plot size. 3) Functional and phylogenetic diversity are stronger predictors for ecosystem functions and stability than taxonomic diversity (Craven et al. 2018; Haoet al. 2018), while richness, evenness and divergence may affect ecosystem functions and stability together (Potter \& Woodall 2014).

\section{MATERIALS AND METHODS}

\section{Study site}

The study site was located at the Xishuangbanna Tropical Botanical Garden (215' N, 101deg46' E) in the Mengla County, Yunnan Province, China. The zonal vegetations here are tropical rain forests and monsoon forests, which is not only a critical region for China's tropical rain forests, but also the northern limit for tropical rain forests in Southeast Asia. The Xishuangbanna region is an important part of the Indo-Burma global biodiversity hotspots, and harbor over 5000 vascular plant species, which account for $16 \%$ of vascular species across China (Cao et al. 2006). The rain forests here not only possess biodiversity that is important both nationally and globally, but also revealed one of the highest forest productivity across China (Fenget al. 1999) as a result of high energy and water availability. Climate in this region is controlled by northern tropical monsoon, with a mean annual temperature of $21.5 \mathrm{degC}$, and mean temperature in June and January of $25.5 \mathrm{deg} C$ and $14.8 \mathrm{deg}$, respectively. Annual precipitation averaged $1557 \mathrm{~mm}$, of which $1335 \mathrm{~mm}(87 \%)$ occurred in the wet season (May to October), while precipitation during the dry season (November to the next April) accounts for only $13 \%$ of annal total. Relative humidity averaged around $80 \%$, and frost was never recorded in this region.

\section{The dataset}

The dataset was provided by the Xishuangbanna National Forest Scientific Observation and Research Station, available at the Chinese Ecosystem Research Network (CERN) (http://www.cnern.org.cn/). The data we downloaded included: 1) repeated measurements of 10 permanent plots $(50 \mathrm{~m} \times 50 \mathrm{~m})$ in the rain forests of Xishuangbanna, including different forest types from secondary to primary forests (Table 1); 2) allometric equations to estimate tree biomass for each forest type (Table S1). 3) Soil variables, including ten soil variables (soil organic carbon, $\mathrm{pH}$, moisture, nitrogen, phosphorous and kalium concentrations, etc.) measured at three locations in each plot in the year of 2010. These 10 plots were established in 2004, each consist of 25 subplots $(10 \mathrm{~m} \mathrm{x} 10 \mathrm{~m})$, which were investigated annually from 2004 to 2010. In each subplot by each year, tree species name and diameter at breast height $(\mathrm{DBH}, 1.3 \mathrm{~m})$ for all individuals with a $\mathrm{DBH}$ [?]1.0 $\mathrm{cm}$ were recorded.

To examine the effect of grain size on the relative importance of diversity vs. stand factors on ecosystem 
functions and stability, we split each 0.25 ha plot into subplots with different sizes: i.e. $400 \mathrm{~m}^{2}, 800 \mathrm{~m}^{2}$ and $1200 \mathrm{~m}^{2}$. As a result, we obtained 61, 30, 20, and 10 (sub)plots with an area of 400, 800, 1200 and $2500 \mathrm{~m}^{2}$, respectively.

\section{Stand biomass, productivity and their stability}

The biomass of each (sub)plot, from 400 to $2500 \mathrm{~m}^{2}$, was calculated by summing the total biomass (stem + branches + foliage + roots) for each tree, which was estimated using the allometric equations that were separately developed for each forest type (Table S1). Annual biomass increment was calculated as the difference in stand biomass between two adjacent years ${ }^{B}=B_{\mathrm{t}}-$ $B_{\mathrm{t}-1}$, where $B_{\mathrm{t}}$ isthestandbiomassof thecurrentyear).Notedthat ${ }^{B}$ doesnotincludelitter fallproductionandthusisaparto fnetpr

To analyze the relationship between diversity and ecosystem functions, we calculated the multi-year mean biomass (2004-2010) and productivity (2005-2010) for each plot (subplot). To explore the effect of diversity on ecosystem stability, we calculated the temporal stability index (Tilman et al. 2006; van der Plas 2019) based on the annual biomass and productivity data for each (sub)plot. Temporal stability is a measure of how community productivity (biomass) fluctuates around its multi-year means: $\mathrm{S}=1 / \mathrm{CV}=\mathrm{v} / \mathrm{\sigma}$, where $u$ is the mean value for a time period and $\boldsymbol{\sigma}$ is the standard deviation over the same interval, while CV is the coefficient of variation (Tilman et al. 2006; van der Plas 2019). Hereafter, the stability of biomass and productivity are abbreviated as S_B, S_P, respectively.

\section{Explanatory variables}

We calculated taxonomic, functional and phylogenetic diversity, and stand factors, to examine their relative effects on biomass, productivity and their stability.

\section{1) Taxonomic diversity}

We calculated species richness and Pielou's evenness for each plot (or subplot) using the 2010 inventory data. Other species diversity indices (e.g. Shannon index) were not included in the final data analyses because of their similar biological meanings and collinearity with richness and evenness. For taxonomic diversity we did not find an index that clearly depict divergence. For instance, Rao's Q is stated to included information on both richness and divergence (Mouchet et al. 2010), but a preliminary analysis revealed that it was highly correlated with species richness. As a result, the divergence of taxonomic diversity was not included in data analyses.

\section{2) Phylogenetic diversity}

To ensure that the species names matched the Angiosperm Phylogeny Group III (APG III, 2009), the Plant List (http://www.theplantlist.org/) database was used to proof read the 351 species names in the plots. Then we generated a phylogenetic tree with branch length for the 337 species using the online program Phylomatic 3 (http://phylodiversity.net/phylomatic/) (Appendix S2), based on the phylogeny of Zanne (2014) which was generated using sequence data of seven gene regions available in GenBank, as well as fossil data. To represent different components (richness, evenness and divergence) of phylogenetic diversity, we calculated three indices as follows. Phylogenetic species variability (PSV) quantifies how phylogenetic relatedness decreases the variance of a hypothetical trait shared by all species in a community, and is used here as a metric for divergence (Helmus et al. 2007; Potter \& Woodall 2014). Phylogenetic species richness (PSR) is calculated as the number of species in a community multiplied by the community's PSV. Phylogenetic species evenness (PSE), on the other hand, is the metric of PSV modified to incorporate relative species abundances (Helmus et al. 2007). All phylogenetic diversity indices are calculated using the R package "picante" (Kembel et al. 2010).

\section{3) Functional diversity}

Previous studies have shown that maximum tree height and wood density were key functional traits to predict forest biomass and productivity (Ruiz-Benito et al. 2014; Woodall et al. 2014; Wu et 
al. 2015b). Consequently, we calculate functional diversity based on these two traits. The maximum tree height data for each species was obtained from the "Flora of China" (Editorial Committee of Flora of China, 2004). The wood density data were retrieved from the global wood density database (http://datadryad.org/repo/handle/10255/dryad.235) and China Woody Plant Wood Density Database (Zhang et al. 2011). To represent the three diversity components, we calculated functional richness (FRic), functional evenness (FEve), and functional divergence (FDiv) for each (sub)plot. FRic is the amount of niche space filled by species in the community, while FEve is the evenness of abundance distribution in filled niche space, and FDiv is the degree to which abundance distribution in niche space maximizes divergence in functional characters within the community (Mason et al. 2005). All functional diversity indices were calculated with the R package "FD" (Laliberté \& Legendre 2010).

\section{4)Stand and soil factors}

We calculated stand total basal area (TBA), maximum breast diameter $\left(\mathrm{DBH}_{\max }\right)$ and stand density for all plots (or subplots). TBA was excluded from final data analyses, because of its collinearity with $\mathrm{DBH}_{\max }$. Unlike TBA which is correlated with both $\mathrm{DBH}$ and density, $\mathrm{DBH}_{\max }$ and stand density were selected for statistical analyses because they reflects distinctive stand structural attributes, and previous studies have also shown that they may have important effects on biomass and productivity (Lutz et al. 2018; Ouyang et al. 2019).

In preliminary analyses, we have also used the ten soil variables (see "The dataset" section) as environmental factors. However, the soil variables were not significantly correlated with the four response variables in most cases, and were rarely retained in the final multivariate models. This is not surprising because the ten plots were located within a relatively small region and thus not differed much in site condition (http: //www.cnern.org.cn/). Consequently, in the final data analyses we excluded the soil variables to focus on the relative importance of stand factors vs. diversity on ecosystem function and stability.

\section{Data analyses}

\section{1)Analyses based on all (sub)plots}

Prior to data analyses all variables were Z-score standardized to avoid the difference in dimension among variables. To examine Questions $1^{\sim} 3$, we explained biomass, productivity and their stability (S_B, S_P) with two groups of variables as follows: 1) Biodiversity, including eight variables depicting the richness, evenness and divergence of species, functional and phylogenetic diversity, as mentioned above; 2) Stand factors, including stand density and $\mathrm{DBH}_{\max }$.

In addition to bivariate analyses, we used model selection based on modified Akaike information criterion (AICc) to obtain the most parsimonious model, so as to identify the major factors affecting ecosystem functions and stability. Model selection was conducted with the "dredge" function in the MuMIn package of $\mathrm{R}$, which select the optimal model based on both the lowest AICc value and the least number of predictors (Bartoń 2016). To evaluate the relative importance for variables retained in the models, we calculated Chi-square values for mixed-effect models $\left(400,800\right.$, and $1200 \mathrm{~m}^{2}$ subplots), while F-value for models of the $2500 \mathrm{~m}^{2}$ plots. The 400,800 and $1200 \mathrm{~m}^{2}$ subplots were split from the $2500 \mathrm{~m}^{2}$ plots, and thus were statistically not fully independent among subplots within a same plot. Consequently, for these subplots we used mixed-effect models with plot as a random effect, which were then submitted to the MuMIn package for model selection. Mixed-effect model analyses were implement with the R package "nlme". For the 2500 $\mathrm{m}^{2}$ plots, ordinary multiple regression was used. However, because of the limited sample size (10 plots), a maximum of seven predictors were allowed by the model selection procedure with the MuMIn package. As a result, we selected five out of eight diversity indices (i.e. species richness and evenness, PSR, PSV and Fric), which showed stronger correlations with the four response variables, to be used in the initial models of the $2500 \mathrm{~m}^{2}$ plots (together with stand density and $\mathrm{DBH}_{\max }$ ).

\section{2) Analyses based on random sampling}

In the above-mentioned analyses, the sample size differed markedly among grain sizes [the number of 400, 
$800,1200 \mathrm{~m}^{2}$ and $2500 \mathrm{~m}^{2}$ (sub)plots was 61,30, 20 and 10, respectively]. In case that the difference in sample size would affect the statistical results, we randomly extracted a same number (14) of subplots for the 400, 800 and $1200 \mathrm{~m}^{2}$ grain sizes, which were fitted with mixed-effect model and then submitted to model selection (as mentioned above). This procedure was repeated for 200 iterations. We sampled 14 subplots because this was the least sample size (which was closer to the 10 sample size of $2500 \mathrm{~m}^{2}$ plots) allowed by the MuMin package when we wanted to use 10 candidate predictors in a mixed effect model. For the 2500 $\mathrm{m}^{2}$ plots, we did not conduct random sampling analyses because of the limited sample size (10) compared with number of predictors (see above), and the results were listed only for reference.

In each iteration, for the variables retained in the model, we used variation partitioning analyses to decompose the total variations in a response variable into four components (Borcard et al. 1992): the pure effect of stand factors $(a)$ and diversity $(b)$, respectively; the joint effect of stand factors and diversity $(c)$, and unexplained variations $(u)$ (see Fig. S3 for an illustration). Note that the pure effect of diversity is the explanatory power when the effect of stand factors has been already accounted for (Schmid et al. 2009, Wu et al. 2015), and thus it may be argued that the biodiversity effect may be underestimated by this metric (the situation is also true for stand factors). Consequently, we also reported the total effect for both diversity (i.e. $a+c)$ and stand factors $(b+c)$ ). In some iterations, only stand factors (or diversity indices) were retained in the model, in this situation both the total and pure effects were equal to the model $\mathrm{R}^{2}$. In a next step, we calculated the mean pure and total effects for diversity (or stand factors) over the 200 iterations, to measure the relative effect of diversity (or stand factors) on each response variable (i.e. biomass, productivity and their temporal stability). We used these results for a more robust evaluation of the relative importance of diversity vs. stand factors (Question 1), and how their relative effects changed with plot size (Question 2).

Finally, to examine the relative roles of different diversity dimensions and components (Question 3), we also calculated variable importance for the variables retained in the model, for each iteration of the 200 random samplings. We conducted hierarchy partitioning analyses using the "hier.part" function in hier.part package in R (Walsh \& Nally. 2020). In each iteration, we recorded the importance value of each diversity or stand factor variable (when a variable was excluded from the model, it's importance value was 0), and model $\mathrm{R}^{2}$. In the "hier.part" function, variable importance is calculated as the percentage of independent contribution to model $\mathrm{R}^{2}$ by each variable in the model (Walsh et al. 2004). However, the model $\mathrm{R}^{2}$ in different iterations might differ markedly, and thus the variable importance was not well comparable among iterations (for instance, FRic may contribute to $80 \%$ in a model with an $\mathrm{R}^{2}$ of 0.3 , but may contribute to $50 \%$ of a model $\mathrm{R}^{2}$ of 0.8). Consequently, we calculated "variable importance" in each iteration as the product of model $\mathrm{R}^{2}$ and the importance value obtained by hier.part. Then the importance of a diversity dimension (or a component) was calculated by averaging the importance of corresponding diversity indices (e.g. importance of the richness component = averaged "variable importance" for species richness, FRic and PSR). In a final step, we averaged the resulting importance values across the 200 iterations to evaluate the relative effects of different diversity dimensions (or components) on ecosystem functions and stability.

All statistical analyses were performed with R 3.6.0 (R Development Core Team, 2019).

\section{RESULTS}

\section{Bivariate relationships of diversity, stand factors with ecosystem functions and stability}

Both stand biomass and productivity were strongly correlated with $\mathrm{DBH}_{\max }\left(\mathrm{r}=0.68^{\sim} 0.92\right)$, at each grain size from 400 to $2500 \mathrm{~m}^{2}$ (Table 1 ). However, they were only occasionally related to diversity indices significantly, except for FRic, which still showed correlations markedly lower than $\mathrm{DBH}_{\max }$. In contrast, the stabilities of biomass and productivity were significantly related to diversity at most grain sizes, especially for richness metrics (taxonomic, phylogenetic and functional richness), but were rarely related to stand factors. These results imply that stand factors may be the main drivers for forest biomass and productivity, while diversity may be mainly responsible for their temporal stability.

\section{Relative importance of stand factors vs. diversity}


The optimal model obtained by model selection based on all (sub)plots showed that (Table 3), for stand biomass and productivity, $\mathrm{DBH}_{\max }$ was the most powerful predictor at each grain size (as indicated by the chi-square or $\mathrm{F}$ values). Meanwhile, diversity indices entered the models only occasionally and revealed weak effect. For ecosystem stability, however, diversity indices play a dominant role at all grain sizes, while stand factors were excluded from all models.

\section{Changes of the relative importance of diversity vs. stand factors with grain size}

The models in Table 3 were based on (sub)plots that differed markedly in sample size, consequently we randomly extracted a same number of subplots for a better comparison across grain sizes (see Methods). Figure 1 again showed that, for forest biomass and productivity, stand factors revealed a markedly stronger effect than diversity indices at each grain size (especially for biomass), no matter measured by the pure or total effect. This confirms our conjecture that stand factors are dominant in driving forest biomass and productivity. However, we also noted that the total and pure effects of diversity on biomass both showed an increase from the 400 to $1200 \mathrm{~m}^{2}$ grain size (for the $2500 \mathrm{~m}^{2}$ results, see below). For productivity, the total effect of diversity increased with grain size while the pure effect decreased, suggesting that the joint effect between diversity and stand factors increased with lager plot size. We thus concluded that the biodiversity effect on forest biomass and productivity might increase with grain size.

For the stability of biomass and productivity, however, the total and pure effects of diversity were markedly higher than that of stand factors across grain sizes, confirming that diversity is dominant in affecting ecosystem stability. However, the total and pure effects of diversity and stand factors on the two stability metrics did not revealed a consistent pattern across grain sizes.

For comparison with the above results based on random sampling of subplots, we also reported the variation partitioning analyses based on models in Table 3 (Fig. S3). We found that while the basic results were similar (stand factors were important for biomass and productivity, while diversity was dominant for stability), there were also notable differences. For biomass and productivity, diversity occasionally showed higher explanatory power in Fig. S3 compared with that in Fig. 1, while at other grain sizes diversity was excluded from the models in Fig. S3. Meanwhile, the explanatory power of diversity from 400 to $1200 \mathrm{~m}^{2}$ in Fig. S3 were ca. $23 \%$ and $20 \%$ for biomass and productivity, respectively, which were clearly lower than that in Fig. 1 (ca. $40 \%$ and $37 \%$, respectively). These differences suggest that the results based on random sampling of plots may be more robust (see Discussions for details). Consequently, the results of the $2500 \mathrm{~m}^{2}$ (which was not based on random sampling) should be viewed with caution, and was listed in Fig. 1 for reference only, and not reported in subsequent analyses.

\section{The relative importance of different diversity components and dimensions}

The results based on random sampling of the subplots showed that (Figure 2), functional diversity (including the effect of richness, evenness and divergence) seemed to be more important for biomass and productivity than phylogenetic and taxonomic diversity, and the importance of functional diversity increases markedly with larger grain size. Thus the increase in the explanatory power of diversity in Figures 1A and 1B may be mainly caused by functional diversity. For biomass stability, functional diversity is also clearly more important than phylogenetic and taxonomic diversity, while the three dimensions of diversity showed similar importance on productivity stability. Meanwhile, the relative importance of three diversity dimensions did not reveal a consistent trend across grain sizes, which may be why the effect of diversity did not show a clear pattern with plot size in Figures 1C and 1D.

As for the three components of diversity (Figure 3), the importance of richness (mean importance of species, functional and phylogenetic richness) on ecosystem functions and stability were generally higher than that of evenness and divergence. However, for biomass and productivity, the importance of divergence increase with grain size. While for the two stability measures, the change of importance value with grain size differed among three diversity components.

\section{DISCUSSION}




\section{Stand factors are more important than diversity in affecting forest biomass and productivity}

Our results revealed the clearly dominant effect of $\mathrm{DBH}_{\max }$ on forest biomass and productivity across all grain sizes (Table 3 and Fig. 1). According to the metabolic theory of ecology, the metabolic rate of an organism scales as a power function of it's body mass (Brown et al. 2004), which means that larger trees accumulate organic matter (i.e. productivity) much faster than small ones, and thus further lead to unproportionally higher biomass. Consistent with this theory, increasing studies have shown that $\mathrm{DBH}_{\max }$ or maximum tree height are good surrogates of plot biomass (Wang et al. 2013; Wu et al. 2015b; Bastinet al. 2018; Lutz et al. 2018), and that large trees are predominant contributors to forest productivity (Xu et al. 2019).

We found that diversity has a weak effect on biomass and a medium effect on productivity (Fig. 1), which provided some supports to the complementary effect hypothesis. However, the effect of diversity is clearly weaker than that of stand factors, which is consistent with recent findings (Ouyang et al. 2019; Staples et al. 2019). These increasing evidences suggest that previous BEF studies may have put too much emphasis on the effects of diversity (van der Plas 2019) compared with stand factors. Forest ecosystems have complex community structures, and many studies have found that stand structure attributes are strong predictors for community biomass or productivity (Wu et al. 2015b; Fotis et al. 2018; Gough et al. 2019). Further, studies have reported that the species-poor planted forests can have biomass and productivity that were comparable to (or even higher than) natural forests with higher diversity (Guo \& Ren 2014), which also suggests that diversity may not be the main driver of forest biomass and productivity compared with stand factors.

\section{Diversity is the main driver of ecosystem stability}

In contrast to biomass and productivity, we found that the relative importance of diversity is much higher than stand factors for ecosystem stability at different grain sizes (Table 3 and Fig. 1). In more-diverse communities, the growth and development of coexisting species are often asynchronous in time and space, which allows the community to stabilize ecosystem functions under environmental perturbations (Loreau \& de Mazancourt 2013; Morinet al. 2014). The asynchrony of coexisting species is mainly determined by the species-specific attributes (such as functional traits, evolutionary history, etc.), and these differences in species attributes can be reflected by diversity indices (e.g. taxonomic, phylogenetic and functional diversity) (Mori et al.2013; del Río et al. 2017). This may be why diversity metrics were powerful in explaining ecosystem stability in our analysis. Hector et al. (2010) proposed the over-yielding effect hypothesis, which suggests that diversity may also stabilize ecosystem functions under environmental disturbances by increasing community biomass or productivity. However, the hypothesis was not well supported, because we found that the influence of diversity on biomass and productivity was weak, and thus the over-yielding effect seem not to be the main driver for ecosystem stability. Recent studies have also shown that the relationship between diversity and ecosystem stability is mainly shaped by the asynchrony of species' response to environmental fluctuation and interactions among species, instead of the over-yielding effect (del Ríoet al. 2017).

It is also suggested that diversity can increase ecosystem stability through species facilitation, which was found to reduce mortality caused by climate events such as drought (Fichtner et al. 2017; Hutchison et al. 2018; Schnabel et al. 2019). Under disturbances or environmental changes, the asynchrony, facilitation and species interactions may be the main drivers of ecosystem stability, and thus the difference in attributes among coexisting species (i.e. diversity indices) may be more important than stand factors. Recent studies have reported that taxonomic diversity explained forest stability better than structural diversity (Schnabel et al. 2019), which also provided some supports to our finding that stand factors showed weak effect on stability. However, analyses on the relative effect of stand factors vs. diversity on ecosystem stability are still limited till now (Mazzochiniet al. 2019; Wang et al. 2019), and the mechanisms why stand factors are so weak predictors of ecosystem stability across grain sizes is still largely unknown (considering the dominant effect of stand factors on biomass and productivity per se, this is surprising). More studies are needed to test our findings and to better understand the underlying mechanisms.

The role of different dimensions and components of diversity 
We found that functional diversity showed stronger effect on forest productivity than taxonomic and phylogenetic diversity (Fig. 2), which is consistent with recent findings (Craven et al. 2018; Haoet al. 2018; Mazzochini et al. 2019; Staples et al.2019). This is somehow not surprising because functional diversity is designed to reflect the functional differences among coexisting species that may not be well captured by taxonomic and phylogenetic diversity, but are more closely related to species niches and thus ecosystem functions (Petchey \& Gaston 2006). Interestingly, we also found markedly higher effect of functional diversity than taxonomic and phylogenetic diversity on biomass stability, though not for the temporal stability of productivity. Plant functional traits may affect the resistance, resilience and stability of communities through mechanisms as follows (Mori et al. 2013; Schnabel et al. 2019): communities dominated by fast-growth strategy species may have higher resilience, while communities dominated by slow-strategy species may have higher resistance. Consequently, communities with higher mixture of species strategies from fast-growth to slow-growth can exhibit both greater resistance and resilience, and thus higher ecosystem stability. However, this hypothesis can only explain our findings for biomass stability, but not for productivity stability. A recent study also reported that taxonomic and phylogenetic diversity stabilized community productivity through enhanced asynchrony of coexisting species, while functional diversity revealed a weak effect (Craven et al . 2018). Biomass and productivity are distinctive types of ecosystem functions (stock and rate, respectively), which have been shown to be affected by diversity differently in both manipulation experiments and natural forests (Caspersen \& Pacala 2001). Our results are consistent them and suggest that the mechanisms how different diversity dimensions affect forest stability is different between carbon stock and carbon assimilation rate, which still needs further studies to examine why, because such knowledge is critical for sustainable forest managements with different management purposes (Craven et al. 2018).

As for different diversity components, we found that richness was generally the strongest predictor of biomass and productivity and their stability, but evenness and dispersion also played a role (Fig. 3). Richness is an indicator of the quantity of species number, functional space, and phylogenetic distance among species. The higher the richness, the more spatial and temporal niches are occupied by coexisting species in the community (Laliberté \& Legendre 2010), which can increase the complementary and asynchrony in space and time and thus increased ecosystem productivity and stability. As for evenness and dispersion, some studies have shown that they can also significantly improve ecosystem functions and stability (Zhang et al. 2012; Potter \& Woodall 2014). The relative weaker effect of evenness and dispersion than richness observed in our study may suggest that: the volume of niche space (i.e. amount of resources) occupied by a community is more important for ecosystem functions and stability, while how the niche space is filled by coexisting species (as reflected by evenness and dispersion, see Mason et al . 2005) plays a second role.

\section{Scale dependence of the diversity effect.}

Previous studies have showed that the relationship between diversity and productivity (biomass) changed with plot size (Chisholm et al.2013; Thompson et al. 2018; Luo et al. 2019). We also found that the explanatory power of diversity increased from the 400 to $1200 \mathrm{~m}^{2}$ grain size for biomass and productivity (Fig. 1). It is generally hypothesized that the biodiversity effect will first increase with larger plot size, and then show a decrease. At smaller plot sizes, environmental heterogeneity increases with increased grain size and thus biodiversity also accumulates, which lead to higher biodiversity effect. However, when diversity gradually saturates with further increase in grain size, the effect of diversity on ecosystem functions will weaken (Chisholm et al . 2013, Thompson et al. 2018). As for the grain size with the strongest diversity effect on forest biomass and productivity, (Chisholm et al. 2013) found that the optimal grain size was 0.04 ha, and that biodiversity effect may become null or even negative for plot size $>0.1$ ha. However, later studies suggest that the optimal grain size is around 0.1 ha (Thompson et al. 2018). Our results suggest that the optimal grain size may be larger than $1200 \mathrm{~m}^{2}$ for forest biomass and productivity. A recent study also found that the diversity effect is the strongest at a grain size of 0.25 ha in a temperate forest (Luo et al. 2019). These results are clearly different from previous idea that biodiversity effect should be the strongest at the smallest grain size, where community processes (e.g. complimentary and sampling effect) play a dominant role (Chisholm et al. 2013). 
Compared with forest biomass and productivity per se, the change of diversity effect on their stability with grain size has much less been reported with field data. However, Wang et al. (2014) proposed a theoretical model and predicted that ecosystem stability itselfshould increase from local to regional scales. As for diversity-stability relationship, their model predicts distinctive pattern between the local and regional scales: 1) at the local community scale, the diversity-stability relationship do not change with grain size; 2) while at the regional (metacommunity) scale, ecosystem stability should be higher with both increasing diversity and grain size. Interesting, our results obtained at the community scale also showed that the effect of diversity on biomass and productivity stability did not showed clear trend across grain sizes (Fig. 1), and thus provide support to their first prediction. Meanwhile, their second prediction is also consistent with a large-scale study, which found that the effect of biodiversity on productivity stability was stronger at a larger grid size of $\sim 55 \mathrm{~km}\left(0.5^{\circ}\right)$ than the $\sim 5 \mathrm{~km}$ grids (Mazzochini et al. 2019). Thus, biodiversity is crucial for ecosystem stability from local community to large scales.

In previous studies that examined the scale dependence of diversity effect, results based on subplots that differed greatly in sample size were generally compared directly (e.g. Chisholm et al. 2013, Thompson et al. 2018, Luo et al. 2019). Our analysis seems to be the first one that test the potential influence of sample size on the scale-dependence of biodiversity effects. Our test showed that while the results based on different subplot numbers (Fig. S3) showed some similarity with that based on random sampling of subplots (Fig. 1), there were also notable differences. For instances, for biomass and productivity, Fig. S3 can not provide a clear picture of increasing diversity effect with larger plot size, as revealed by Fig. 1. However, this difference seems not to be mainly caused by difference in sample size. Instead, it seems to be caused by the fact that: when the diversity effect is weak, diversity indices have higher probability to be excluded from the models, which result in the occasionally high explanatory power of diversity in Fig. S3A and S3B (this is also evident when comparing the effect of stand factors on ecosystem stability between Fig. 1 and Fig. S3). Thus, we suggest the random sampling method may provide a more robust way to examine the relative effect of diversity vs. other factors, and their scale dependence. It remains unclear whether the different optimal grain size found by previous studies (e.g. Chisholm et al. 2013, Thompson et al. 2018) from ours results were caused by this statistic issue. It is a pity that the maximum plot size in our dataset is not large enough. We suggest authors with larger plots to test our method, for a better understanding of the scale dependence of biodiversity effect.

\section{CONCLUSION}

Our results reconcile the recent debate on the relative importance of diversity vs. stand factors on ecosystem properties in natural forests. We showed that forest biomass and productivity are more affected by stand factors, while their temporal stability is dominated by diversity. Notably, our results imply that the effect of diversity on forest biomass and productivity may increase with grain size. Our analysis highlights the importance of forest management to adjust stand structure as an effective way to increase forest biomass and productivity, so as to mitigate global climate change. Meanwhile, biodiversity conservation should be incorporated in forest management practices, which is crucial for ecosystem stability and to sustain ecosystem services under projected future climate change. Our results also suggest that management practices to increase richness and functional diversity may be more effective to enhance ecosystem functions and stability, than other diversity components and dimensions.

\section{Acknowledgements}

This study was supported by the National Key Research and Development Program of China (\#2016YFC0502104, \#2017YFC0503901), and the National Natural Science Foundation of China (\#31870430). Many thanks are due to the National Observation and Research Station of Forest Ecosystem in Xishuangbanna for providing their data, and for Dr. Han Sun for helps in data collection.

\section{References}

Bartoń, K. (2016). MuMIn: Multi-model inference. $\quad R$ package version 1.15.6. , Retrieved fromhttps://CRAN.R-project.org/package=MuMIn. 
Bastin, J.-F., Rutishauser, E., Kellner, J.R., Saatchi, S., Pélissier, R., Hérault, B. et al. (2018). Pan-tropical prediction of forest structure from the largest trees. Global Ecology and Biogeography, 27, 1366-1383.

Bond, E.M. \& Chase, J.M. (2002). Biodiversity and ecosystem functioning at local and regional spatial scales. Ecology Letters, 5, 467-470.

Borcard, D., Legendre, P. \& Drapeau, P. (1992). Partialling out the spatial component of ecological variation. Ecology , 73, 1045-1055.

Brown, J.H., Gillooly, J.F., Allen, A.P., Savage, V.M. \& West, G.B. (2004). Toward a metabolic theory of ecology. Ecology , 85, 1771-1789.

Cadotte, M.W., Dinnage, R. \& Tilman, D. (2012). Phylogenetic diversity promotes ecosystem stability. Ecology , 93, S223-S233.

Cao, M., Zou, X., Warren, M.W. \& Zhu, H. (2006). Tropical Forests of Xishuangbanna, China. Biotropica , 38, 306-309.

Caspersen, J.P. \& Pacala, S.W. (2001). Successional diversity and forest ecosystem function. Ecological Research , 16, 895-903.

Chisholm, R.A., Muller-Landau, H.C., Rahman, K.A., Bebbe, D.P., Bin, Y., Bohlman, S.A. et al. (2013). Scale-dependent relationships between tree species richness and ecosystem function in forests. Journal of Ecology , 101, 1214-1224.

Craven, D., Eisenhauer, N., Pearse, W.D., Hautier, Y., Isbell, F., Roscher, C. et al. (2018). Multiple facets of biodiversity drive the diversity-stability relationship. Nature Ecology 85 Evolution, 2, 1579-1587.

de Mazancourt, C., Isbell, F., Larocque, A., Berendse, F., De Luca, E., Grace, J.B. et al. (2013). Predicting ecosystem stability from community composition and biodiversity. Ecology Letters , 16, 617-625.

del Río, M., Pretzsch, H., Ruíz-Peinado, R., Ampoorter, E., Annighöfer, P., Barbeito, I. et al. (2017). Species interactions increase the temporal stability of community productivity inPinus sylvestris-Fagus sylvaticamixtures across Europe. Journal of Ecology, 105, 1032-1043.

Delsol, R., Loreau, M. \& Haegeman, B. (2018). The relationship between the spatial scaling of biodiversity and ecosystem stability. Global Ecology and Biogeography , 27, 439-449.

Duffy, J.E. (2009). Why biodiversity is important to the functioning of real-world ecosystems. Frontiers in Ecology and the Environment, 7, 437-444.

Feng, Z., Wang, X. \& Wu, G. (1999). Biomass and production of chinese forestry ecosystem . Science and Technology Press, Beijing.

Fichtner, A., Hardtle, W., Li, Y., Bruelheide, H., Kunz, M. \& von Oheimb, G. (2017). From competition to facilitation: how tree species respond to neighbourhood diversity. Ecology Letters , 20, 892-900.

Flynn, D.F.B., Mirotchnick, N., Jain, M., Palmer, M.I. \& Naeem, S. (2011). Functional and phylogenetic diversity as predictors of biodiversity-ecosystem-function relationships. Ecology, 92, 1573-1581.

Fotis, A.T., Murphy, S.J., Ricart, R.D., Krishnadas, M., Whitacre, J., Wenzel, J.W. et al. (2018). Aboveground biomass is driven by mass-ratio effects and stand structural attributes in a temperate deciduous forest. Journal of Ecology , 106, 561-570.

Gough, C.M., Atkins, J.W., Fahey, R.T. \& Hardiman, B.S. (2019). High rates of primary production in structurally complex forests.Ecology .

Guo, Q. \& Ren, H. (2014). Productivity as related to diversity and age in planted versus natural forests. Global Ecology and Biogeography, 23, 1461-1471. 
Hao, M., Zhang, C., Zhao, X. \& von Gadow, K. (2018). Functional and phylogenetic diversity determine woody productivity in a temperate forest. Ecology and Evolution , 8, 2395-2406.

Helmus, M.R., Bland, T.J., Williams, C.K. \& Ives, A.R. (2007). Phylogenetic measures of biodiversity. The American Naturalist, 169, E68-E63.

Hooper, D.U., Adair, E.C., Cardinale, B.J., Byrnes, J.E., Hungate, B.A., Matulich, K.L. et al. (2012). A global synthesis reveals biodiversity loss as a major driver of ecosystem change. Nature, 486, 105-108.

Hooper, D.U., Chapin, F.S., Ewel, J.J., Hector, A., Inchausti, P., Lavorel, S. et al. (2005). Effects of biodiversity on ecosystem functioning: a consensus of current knowledge. Ecol Monogr , 75, 3-35.

Huang, Y., Chen, Y., Castro-Izaguirre, N., Baruffol, M., Brezzi, M., Lang, A. et al. (2018). Impacts of species richness on productivity in a large-scale subtropical forest experiment.Science, ,362, 80-83.

Hutchison, C., Gravel, D., Guichard, F. \& Potvin, C. (2018). Effect of diversity on growth, mortality, and loss of resilience to extreme climate events in a tropical planted forest experiment. Sci Rep-Uk, 8, 15443.

Isbell, F., Calcagno, V., Hector, A., Connolly, J., Harpole, W.S., Reich, P.B. et al. (2011). High plant diversity is needed to maintain ecosystem services. Nature , 477, 199-202.

Isbell, F., Cowles, J., Dee, L.E., Loreau, M., Reich, P.B., Gonzalez, A.et al. (2018). Quantifying effects of biodiversity on ecosystem functioning across times and places. Ecology Letters , 21, 763-778.

Isbell, F., Gonzalez, A., Loreau, M., Cowles, J., Diaz, S., Hector, A.et al. (2017). Linking the influence and dependence of people on biodiversity across scales. Nature , 546, 65-72.

Isbell, F.I., Polley, H.W. \& Wilsey, B.J. (2009). Biodiversity, productivity and the temporal stability of productivity: patterns and processes. Ecology Letters , 12, 443-451.

Jarzyna, M.A. \& Jetz, W. (2016). Detecting the Multiple Facets of Biodiversity. Trends in Ecology \& Evolution, 31 .

Kembel, S.W., Cowan, P.D., Helmus, M.R., Cornwell, W.K., Morlon, H., Ackerly, D.D. et al. (2010). Picante: $\mathrm{R}$ tools for integrating phylogenies and ecology. Bioinformatics , 26, 1463-1464.

Laliberté, E. \& Legendre, P. (2010). A distance-based framework for measuring functional diversityfrom multiple traits. Ecology , 91, 299-305.

Liang, J., Crowther, T.W., Picard, N., Wiser, S., Zhou, M., Alberti, G.et al. (2016). Positive biodiversityproductivity relationship predominant in global forests. Science, 354 .

Loreau, M. (1998). Biodiversity and ecosystem functioning: A mechanistic model. P Natl Acad Sci USA, $95,5632-5636$.

Loreau, M. \& de Mazancourt, C. (2013). Biodiversity and ecosystem stability: a synthesis of underlying mechanisms. Ecology Letters , 16, 106-115.

Luo, W., Liang, J., Cazzolla Gatti, R., Zhao, X., Zhang, C. \& Jucker, T. (2019). Parameterization of biodiversity-productivity relationship and its scale dependency using georeferenced tree-level data.Journal of Ecology, 107, 1106-1119.

Lutz, J.A., Furniss, T.J., Johnson, D.J., Davies, S.J., Allen, D., Alonso, A. et al. (2018). Global importance of large-diameter trees. Global Ecology and Biogeography , 27, 849-864.

Ma, W., He, J.-S., Yang, Y., Wang, X., Liang, C., Anwar, M. et al. (2010). Environmental factors covary with plant diversity-productivity relationships among Chinese grassland sites. Global Ecology and Biogeography , 19, 233-243.

Mason, N.W.H., Mouillot, D., Lee, W.G. \& Wilson, J.B. (2005). Functional richness, functional evenness and functional divergence: The primary components of functional diversity. Oikos , 111, 112-118. 
Mazzochini, G.G., Fonseca, C.R., Costa, G.C., Santos, R.M., Oliveira-Filho, A.T., Ganade, G. et al. (2019). Plant phylogenetic diversity stabilizes large-scale ecosystem productivity. Global Ecology and Biogeography .

Mori, A.S., Furukawa, T. \& Sasaki, T. (2013). Response diversity determines the resilience of ecosystems to environmental change. Biological Reviews 88, 349-364.

Morin, X., Fahse, L., de Mazancourt, C., Scherer-Lorenzen, M. \& Bugmann, H. (2014). Temporal stability in forest productivity increases with tree diversity due to asynchrony in species dynamics. Ecology Letters, $17,1526-1535$.

Mouchet, M.A., Villeger, S., Mason, N.W.H. \& Mouillot, D. (2010). Functional diversity measures: an overview of their redundancy and their ability to discriminate community assembly rules. Functional Ecology , 24, 867-876.

Naeem, S. \& Li, S. (1997). Biodiversity enhances ecosystem reliability.Nature, 390, 507-509.

Ouyang, S., Xiang, W., Wang, X., Xiao, W., Chen, L., Li, S. et al. (2019). Effects of stand age, richness and density on productivity in subtropical forests in China. Journal of Ecology .

Pan, Y., Birdsey, R.A., Fang, J., Houghton, R., Kauppi, P.E., Kurz, W.A.et al. (2011). A large and persistent carbon sink in the world's forests. Science, 333, 988-993.

Pennekamp, F., Pontarp, M., Tabi, A., Altermatt, F., Alther, R., Choffat, Y. et al. (2018). Biodiversity increases and decreases ecosystem stability. Nature, 563, 109-112.

Petchey, O.L. \& Gaston, K.J. (2006). Functional diversity: back to basics and looking forward. Ecology Letters , 9, 741-758.

Poorter, L., van der Sande, M.T., Arets, E.J.M.M., Ascarrunz, N., Enquist, B.J., Finegan, B. et al. (2017). Biodiversity and climate determine the functioning of Neotropical forests. Global Ecology and Biogeography , 26, 1423-1434.

Poorter, L., van der Sande, M.T., Thompson, J., Arets, E.J.M.M., Alarcon, A., Alvarez-Sanchez, J. et al. (2015). Diversity enhances carbon storage in tropical forests. Global Ecology and Biogeography , 24, 1314-1328.

R Development Core Team. (2019). R: A language and environment for statistical computing. R Foundation for Statistical Computing Vienna, Austria

Potter, K.M. \& Woodall, C.W. (2014). Does biodiversity make a difference? Relationships between species richness, evolutionary diversity, and aboveground live tree biomass across U.S. forests. Forest Ecology and Management, 321, 117-129.

Ruijven, J.v. \& Berendse, F. (2005). Diversity-productivity relationships: Initial effects, long-term patterns, and underlying mechanisms. P Natl Acad Sci USA, 102, 695-700.

Ruiz-Benito, P., Gomez-Aparicio, L., Paquette, A., Messier, C., Kattge, J. \& Zavala, M.A. (2014). Diversity increases carbon storage and tree productivity in Spanish forests. Global Ecology and Biogeography , 23, 311-322.

Satdichanh, M., Ma, H., Yan, K., Dossa, G.G.O., Winowiecki, L., Vagen, T.-G. et al. (2019). Phylogenetic diversity correlated with above-ground biomass production during forest succession: Evidence from tropical forests in Southeast Asia. Journal of Ecology , 107, 1419-1432.

Schnabel, F., Schwarz, J.A., Danescu, A., Fichtner, A., Nock, C.A., Bauhus, J. et al. (2019). Drivers of productivity and its temporal stability in a tropical tree diversity experiment. Global Change Biology , 25, 4257-4272. 
Shirima, D.D., Totland, O., Munishi, P.K.T. \& Moe, S.R. (2015). Relationships between tree species richness, evenness and aboveground carbon storage in montane forests and miombo woodlands of Tanzania.Basic and Applied Ecology , 16, 239-249.

Staples, T.L., Dwyer, J.M., England, J.R., Mayfield, M.M. \& Simova, I. (2019). Productivity does not correlate with species and functional diversity in Australian reforestation plantings across a wide climate gradient. Global Ecology and Biogeography .

Thompson, P.L., Isbell, F., Loreau, M., O'Connor, M.I. \& Gonzalez, A. (2018). The strength of the biodiversity-ecosystem function relationship depends on spatial scale. Proceedings of the Royal Society B: Biological Sciences 285.

Tilman, D., Isbell, F. \& Cowles, J.M. (2014). Biodiversity and ecosystem functioning. Annual Review of Ecology, Evolution, and Systematics , 45, 471-493.

Tilman, D., Lehman, C.L. \& Thomson, K.T. (1997). Plant diversity and ecosystem productivity: theoretical considerations. P Natl Acad Sci USA, 94, 1857-1861.

Tilman, D., Reich, P.B. \& Knops, J.M. (2006). Biodiversity and ecosystem stability in a decade-long grassland experiment.Nature , 441, 629-632.

van der Plas, F. (2019). Biodiversity and ecosystem functioning in naturally assembled communities. Biological Reviews 94, 1220-1245.

van der Sande, M.T., Arets, E.J.M.M., Pena-Claros, M., Hoosbeek, M.R., Caceres-Siani, Y., van der Hout, P. et al. (2018). Soil fertility and species traits, but not diversity, drive productivity and biomass stocks in a Guyanese tropical rainforest. Functional Ecology , 32, 461-474.

van der Sande, M.T., Pena-Claros, M., Ascarrunz, N., Arets, E.J.M.M., Licona, J.C., Toledo, M. et al. (2017). Abiotic and biotic drivers of biomass change in a Neotropical forest. Journal of Ecology , 105, 1223-1234.

Walsh, C.J., Papas, P., Crowther, D., Sim, P. \& Yoo, J. (2004). Stormwater drainage pipes as a threat to a stream-dwelling amphipod of conservation significance,Austrogammarus australis, in southeastern Australia. Biodiversity and Conservation, 13, 781-793.

Walsh, C.J., Nally, R.M. (2020). hier.part: Hierarchical Partitioning. R package version 1.0-6. https://cran.r-project.org/web/packages/hier.part/index.html

Wang, B., Tian, C. \& Sun, J. (2019). Effects of landscape complexity and stand factors on arthropod communities in poplar forests. Ecol Evol , 9, 7143-7156.

Wang, S. \& Loreau, M. (2014). Ecosystem stability in space: alpha, beta and gamma variability. Ecol Lett , 17, 891-901.

Wang, X., Swenson, N.G., Wiegand, T., Wolf, A., Howe, R., Lin, F.et al. (2013). Phylogenetic and functional diversity area relationships in two temperate forests. Ecography, 36, 883-893.

Wardle, D., Huston, M.A., Grime, J.P., Berendse, F., Garnier, E. \& Lauenroth, W.K. (2000). Biodiversity and ecosystem function: an issue in ecology. Bulletin of the Ecological Society of America, 81, 235-239.

Woodall, C.W., Russell, M.B., Walters, B.F., D'Amato, A.W., Zhu, K. \& Saatchi, S.S. (2014). Forest production dynamics along a wood density spectrum in eastern US forests. Trees , 29, 299-310.

Wu, X., Wang, X., Tang, Z., Shen, Z., Zheng, C., Xia, X. et al.(2015a). The relationship between species richness and biomass changes from boreal to subtropical forests in China. Ecography, 38, 602-613.

Wu, X., Wang, X., Wu, Y., Xia, X. \& Fang, J. (2015b). Forest biomass is strongly shaped by forest height across boreal to tropical forests in China. Journal of Plant Ecology . 
Xu, K., Wang, X., Liang, P., Wu, Y., An, H., Sun, H. et al.(2019). A new tree-ring sampling method to estimate forest productivity and its temporal variation accurately in natural forests. Forest Ecology and Management , 433, 217-227.

Zhang, S.-B., Slik, J.W.F., Zhang, J.-L. \& Cao, K.-F. (2011). Spatial patterns of wood traits in China are controlled by phylogeny and the environment. Global Ecology and Biogeography , 20, 241-250.

Zhang, Y., Chen, H.Y.H. \& Reich, P.B. (2012). Forest productivity increases with evenness, species richness and trait variation: a global meta-analysis. Journal of Ecology, 100, 742-749.

Table 1. Community characteristics of the 10 permanent forest plots $(50 \mathrm{~m} \times 50 \mathrm{~m})$ in Xishuangbanna, southwest China. Density, $\mathrm{DBH}_{\text {mean }}, \mathrm{DBH}_{\max }$, and TBA are stand density (tree/ha), mean breast diameter $(\mathrm{cm})$, maximum breast diameter $(\mathrm{cm})$ and total basal area $\left(\mathrm{m}^{2} / \mathrm{ha}\right)$, respectively.

\begin{tabular}{lllllll}
\hline Plot ID & Forest type & Density & $\mathrm{DBH}_{\text {mean }}$ & $\mathrm{DBH}_{\max }$ & TBA & Dominant genus \\
\hline BNFFZ01 & secondary forest & 2464 & 8.9 & 118.60 & 50.32 & Barringtonia, Pometia \\
BNFFZ02 & secondary forest & 2724 & 7.7 & 63.60 & 29.24 & Barringtonia, Baccaurea \\
BNFZH01 & monsoon rainforest & 2732 & 7.1 & 82.90 & 34.76 & Barringtonia, Pometia \\
BNFZH02 & monsoon rainforest & 2312 & 7.6 & 146.50 & 37.32 & Barringtonia, Baccaurea \\
BNFZH03 & monsoon rainforest & 2020 & 7.9 & 91.00 & 28.24 & Gironniera, Walsura \\
BNFZH04 & monsoon rainforest & 2712 & 7.39 & 113.90 & 32.88 & Barringtonia, Gironniera \\
BNFZQ01 & karst monsoon forest & 3280 & 7.63 & 81.55 & 29.76 & Cleistanthus \\
BNFZQ02 & secondary forest & 2420 & 6.67 & 35.43 & 13.20 & Syzygium, Millettia, Castanop \\
BNFZQ03 & secondary forest & 2704 & 6.66 & 39.53 & 14.68 & Schefflera, Machilus, Dolichan \\
BNFZQ04 & monsoon evergreen broad-leaf forest & 3272 & 7.3 & 69.96 & 26.60 & Castanopsis, Aporusa, Schima \\
\hline
\end{tabular}

Table 2. Correlation of stand factors and diversity indices with forest biomass, productivity and their stability (S_B and S_P) at different plot size. Only significant relationships $(\mathrm{p}<0.05)$ were listed for clarity. The unit of grain size is $\mathrm{m}^{2}$. Ric is species richness; Eve is species evenness; PSR, PSE, and PSV are phylogenetic richness, phylogenetic evenness and phylogenetic variability, respectively; FRic, FEve, and FDiv are functional richness, evenness and divergence, respectively. Level of significance: $\mathrm{P}<0.001{ }^{* * *}, \mathrm{P}$ $<0.01^{* *}, \mathrm{P}<0.05^{*}$.

\begin{tabular}{|c|c|c|c|c|c|c|c|c|c|c|}
\hline $\begin{array}{l}\text { Ecosystem } \\
\text { proper- } \\
\text { ties }\end{array}$ & $\begin{array}{l}\text { m } \\
\text { Grain } \\
\text { size }\end{array}$ & $\begin{array}{l}\text { Stand } \\
\text { factors }\end{array}$ & $\begin{array}{l}\text { Stand } \\
\text { factors }\end{array}$ & $\begin{array}{l}\text { Taxonc } \\
\text { diver- } \\
\text { sity }\end{array}$ & $\begin{array}{l}\text { idaxon } \\
\text { diver- } \\
\text { sity }\end{array}$ & $\begin{array}{l}\text { iæhylog } \\
\text { diver- } \\
\text { sity }\end{array}$ & $\begin{array}{l}\text { ellikylos } \\
\text { diver- } \\
\text { sity }\end{array}$ & $\begin{array}{l}\text { ellikylo } \\
\text { diver- } \\
\text { sity }\end{array}$ & $\begin{array}{l}\text { ellioncti } \\
\text { diver- } \\
\text { sity }\end{array}$ & $\begin{array}{l}\text { aFunction } \\
\text { diver- } \\
\text { sity }\end{array}$ \\
\hline \multirow{4}{*}{ Biomass } & & $\mathrm{DBH}_{\text {max }}$ & Density & Ric & Eve & PSR & PSE & PSV & FRic & FEve \\
\hline & $\begin{array}{l}400 \\
800\end{array}$ & $0.86^{* *}$ & & & & o * & & & $0.29^{*}$ & \\
\hline & $\begin{array}{l}000 \\
1200\end{array}$ & $0.91^{* *}$ & & & & $0.39^{*}$ & & & & \\
\hline & 2500 & $0.91^{* *}$ & & & & & & & & \\
\hline \multirow{2}{*}{\multicolumn{2}{|c|}{ Productivillogo }} & $0.68^{* *}$ & - & & & & & & $033^{*}$ & \\
\hline & & & $0.26^{*}$ & & & & & & & \\
\hline \multirow{8}{*}{$\mathbf{S} \_\mathbf{B}$} & 800 & $0.74^{* *}$ & & & & $0.37^{*}$ & & & $0.43^{*}$ & \\
\hline & 1200 & $0.73^{* *}$ & & & & & & & $0.46^{*}$ & \\
\hline & 2500 & $0.77^{* *}$ & & & & & & & & \\
\hline & 400 & & & $0.28^{*}$ & & $0.27^{*}$ & & & $0.37^{*}$ & \\
\hline & 800 & & & $0.43^{*}$ & & $0.42^{*}$ & & & $0.45^{*}$ & \\
\hline & 1200 & & & $0.48^{*}$ & & $0.47^{*}$ & & & $0.51^{*}$ & \\
\hline & 2500 & & & & & & & - & & \\
\hline & & & & & & & & $0.66^{*}$ & & \\
\hline
\end{tabular}




\begin{tabular}{|c|c|c|c|c|c|c|c|c|c|c|}
\hline \multicolumn{4}{|c|}{ Ecosystem } & \multicolumn{7}{|c|}{ TaxonomiTaxonomiPhylogenePikylogenelPikylogeneftimctionaFunction } \\
\hline $\begin{array}{l}\text { proper- } \\
\text { ties }\end{array}$ & $\begin{array}{l}\text { Grain } \\
\text { size }\end{array}$ & $\begin{array}{l}\text { Stand } \\
\text { factors }\end{array}$ & $\begin{array}{l}\text { Stand } \\
\text { factors }\end{array}$ & $\begin{array}{l}\text { diver- } \\
\text { sity }\end{array}$ & $\begin{array}{l}\text { diver- } \\
\text { sity }\end{array}$ & $\begin{array}{l}\text { diver- } \\
\text { sity }\end{array}$ & $\begin{array}{l}\text { diver- } \\
\text { sity }\end{array}$ & $\begin{array}{l}\text { diver- } \\
\text { sity }\end{array}$ & $\begin{array}{l}\text { diver- } \\
\text { sity }\end{array}$ & $\begin{array}{l}\text { diver- } \\
\text { sity }\end{array}$ \\
\hline \multirow[t]{4}{*}{$\mathbf{S} \_\mathbf{P}$} & 400 & & & $0.34^{*}$ & & $0.34^{*}$ & & & $0.38^{*}$ & \\
\hline & 800 & $0.37^{*}$ & & $0.36^{*}$ & & $0.37^{*}$ & & & $0.36^{*}$ & \\
\hline & 1200 & & & & & & & & & \\
\hline & 2500 & & & $0.68^{* *}$ & $0.69^{* *}$ & $0.68^{* *}$ & & & $0.63^{* *}$ & \\
\hline
\end{tabular}

Table 3. Optimal models for the effects of stand factors and diversity on forest biomass, productivity and their stability (S_B and S_P, respectively) at different plot sizes, obtained through model selection procedure. For the grain sizes from 400 to $1200 \mathrm{~m}^{2}$, we used mixed-effects models and thus the chi-square values were reported for variables retained in the model. While for the $2500 \mathrm{~m}^{2}$ grain size, we used ordinary regression and thus $\mathrm{F}$ values were reported (see Methods for details).

\begin{tabular}{llll}
\hline Ecosystem properties & Grain size & Variables retained in the model (chi-square or F values) & Model R $^{\mathbf{2}}$ \\
\hline Biomass & 400 & DBH $_{\max }(170.81)$ & 0.74 \\
& 800 & DBH $_{\max }(149.93)+$ Richness $(6.95)+$ PSR $(6.91)$ & 0.88 \\
& 1200 & DBHmax $(88.19)$ & 0.83 \\
Productivity & 2500 & DBHmax $(36.27)$ & 0.82 \\
& 400 & DBHmax $(46.07)+$ Density $(2.46)$ & 0.48 \\
& 800 & DBHmax $(30.48)+$ FRic $(6.32)+$ PSR $(4.32)$ & 0.64 \\
S_B & 1200 & DBHmax $(20.54)$ & 0.53 \\
& 2500 & DBHmax (11.84) & 0.60 \\
& 400 & FRic $(17.61)+$ PSE $(7.03)$ & 0.23 \\
S_P & 800 & FRic $(7.29)$ & 0.21 \\
& 1200 & FRic $(6.47)$ & 0.26 \\
& 2500 & PSV $(6.18)$ & 0.44 \\
& 400 & FRic $(10.14)$ & 0.15 \\
& 800 & PSR $(5.86)+$ FDiv $(4.02)$ & 0.25 \\
& 1200 & PSR $(2.82)$ & 0.14 \\
\hline
\end{tabular}



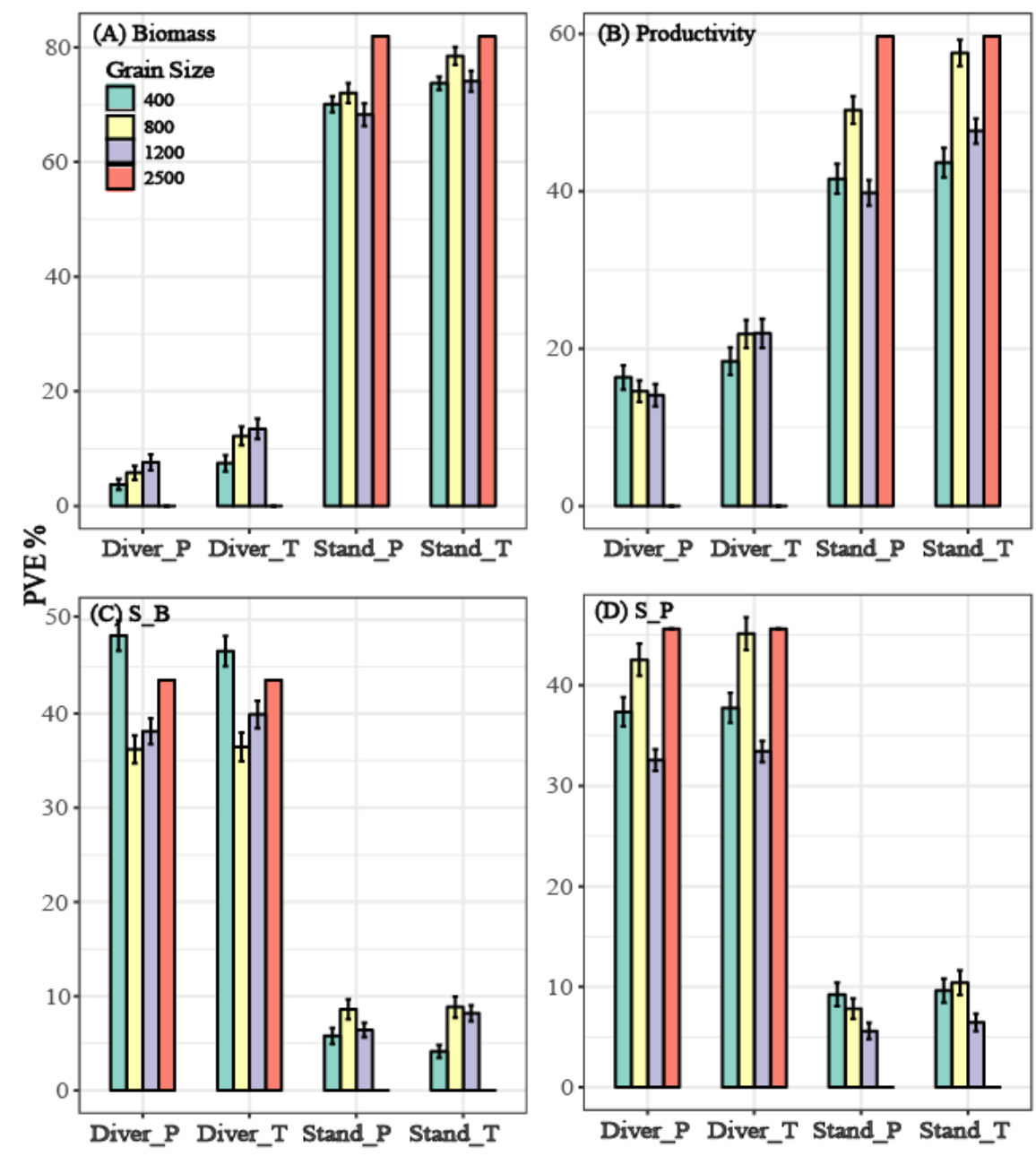

Figure 1. Variation partitioning analysis for the relative importance of stand factors vs. diversity in explaining forest biomass (A), productivity (B) and their stability (C and D, respectively) at different plot size. For the 400, 800 and $1200 \mathrm{~m}^{2}$ grain size, we reported the mean percentage of variations explained (PVE), and the standard error, during the 200 sampling of 14 subplots (see Methods). The $2500 \mathrm{~m}^{2}$ results were based on models in Table 3. Abbreviations: Diver_T, Diver_P, Stand_T and Stand_P, the total and pure effect of diversity indices, and the total and pure effect of stand factors, respectively. 


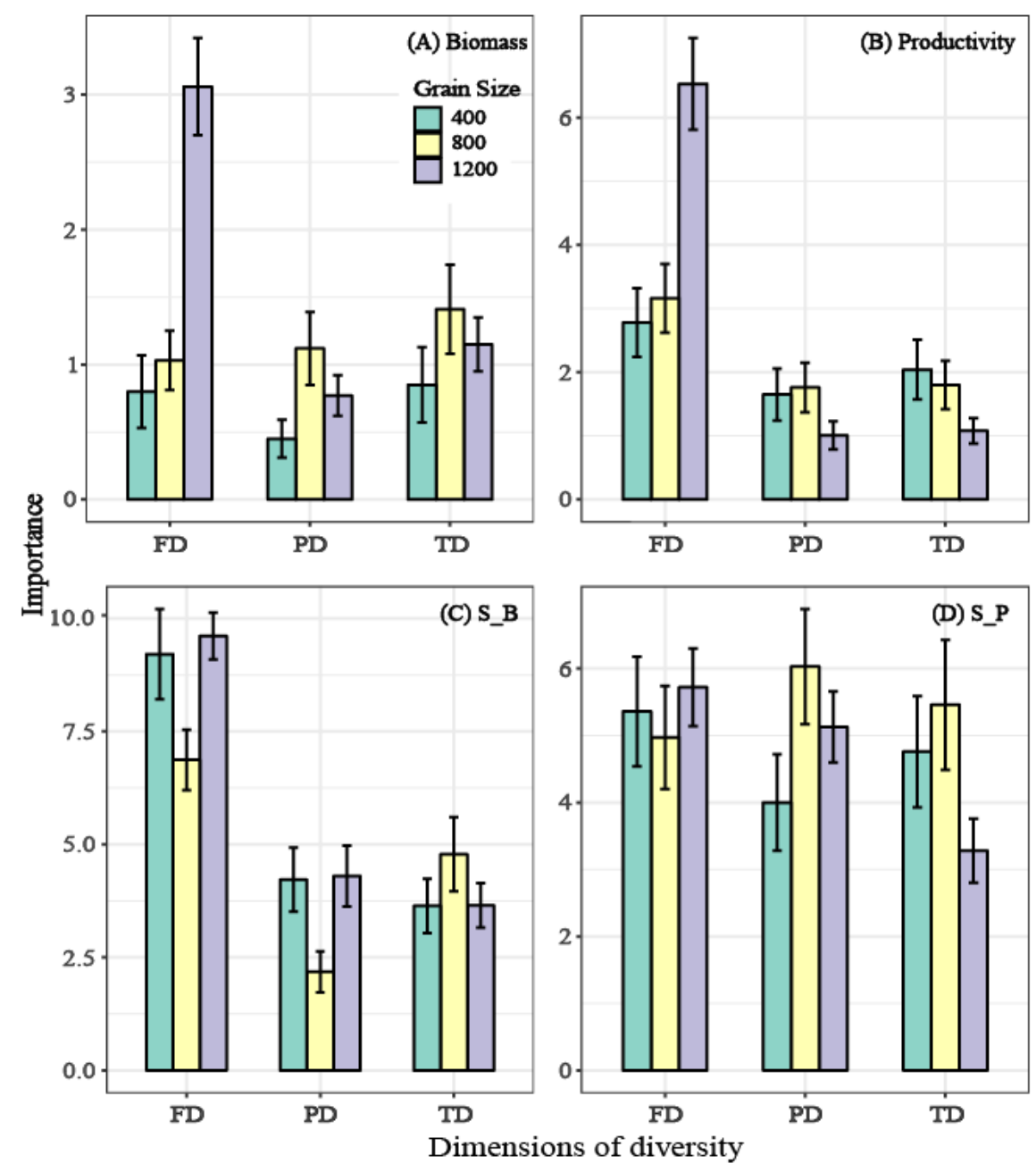

Figure 2. The relative importance of three diversity dimensions in explaining stand biomass (A), productivity (B) and their stability (C and D, respectively), as obtained by hierarchy partitioning analysis. For each grain size, the mean variable importance (and standard error) over 200 random samplings of subplots were reported. TD, taxonomic diversity; PD, phylogenetic diversity; FD, functional diversity. 


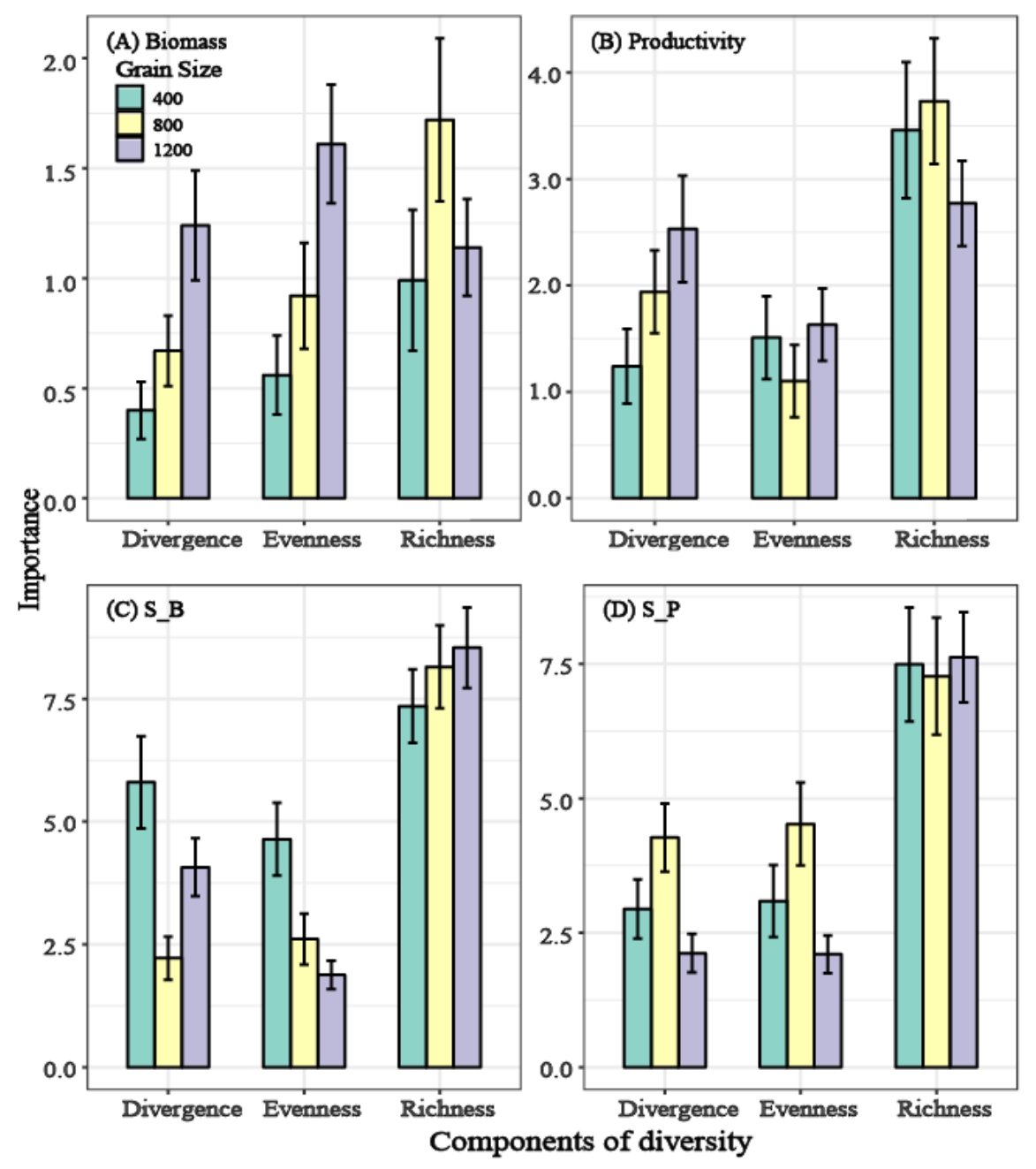

Figure 3. The relative importance of different diversity components in explaining stand biomass (A), productivity (B) and their stability (C and $\mathrm{D}$, respectively), as obtained by hierarchy partitioning analysis. For each grain size, the mean variable importance (and standard error) over 200 random samplings were reported.

\section{APPENDIX 1: SUPPLEMENTAL TABLES AND FIGURES}

Tables S1

Figures S1-S3

Appendices

Table S1. Biomass equations of each forest type in this study, as developed by the Xishuangbanna Tropical Botanical Garden. $a, b$ and $c$ are the fitted parameters; $r^{2}$ is the coefficient of determination; $B_{r}, B_{s}, B_{b a r k}$, $\mathrm{B}_{\mathrm{b}}, \mathrm{B}_{\mathrm{l}}$ are the biomass $(\mathrm{B}, \mathrm{kg})$ of root, stem, bark, branch and leaf, respectively; $\mathrm{D}$ is the diameter $(\mathrm{DBH}$, $\mathrm{cm})$ at breast height; $\mathrm{H}$ is the tree height $(\mathrm{H}, \mathrm{m})$

\begin{tabular}{lllll}
\hline Forest type & Range $_{-\mathbf{D B H}}$ & Equation & $\mathbf{a}$ & $\mathbf{b}$ \\
\hline Karst monsoon forest & $1.0^{\sim} 5.0$ & $\mathrm{~B}_{\mathrm{r}}=\mathrm{a}^{*} \mathrm{D}^{\mathrm{b}}$ & 0.041 & 2.156 \\
& & $\mathrm{~B}_{\mathrm{s}}=\mathrm{a}^{*} \mathrm{D}^{\mathrm{b}}$ & 0.099 & 2.469
\end{tabular}




\begin{tabular}{|c|c|c|c|c|}
\hline Forest type & Range_DBH & Equation & $\mathbf{a}$ & $\mathbf{b}$ \\
\hline & & $\mathrm{B}_{\mathrm{bark}}=\mathrm{a}^{*} \mathrm{D}^{\mathrm{b}}$ & 0.016 & 2.123 \\
\hline & & $\mathrm{B}_{\mathrm{b}}=\mathrm{a}^{*} \mathrm{D}^{\mathrm{b}}$ & 0.037 & 2.315 \\
\hline & & $\mathrm{B}_{\mathrm{l}}=\mathrm{a} * \mathrm{D}^{\mathrm{b}}$ & 0.028 & 1.961 \\
\hline & $5.0^{\sim} 20.0$ & $\mathrm{~B}_{\mathrm{r}}=\mathrm{a}^{*} \mathrm{D}^{\mathrm{b}}$ & 0.028 & 2.469 \\
\hline & & $\mathrm{B}_{\mathrm{s}}=\mathrm{a}^{*} \mathrm{D}^{\mathrm{b}}$ & 0.119 & 2.331 \\
\hline & & $\mathrm{B}_{\mathrm{b}}=\mathrm{a}^{*} \mathrm{D}^{\mathrm{b}}$ & 0.015 & 2.733 \\
\hline & & $\mathrm{B}_{\mathrm{l}}=\mathrm{a} * \mathrm{D}^{\mathrm{b}}$ & 0.043 & 2.469 \\
\hline & $20.0^{\sim} 88.4$ & $\mathrm{~B}_{\mathrm{r}}=\mathrm{a}^{*} \mathrm{D}^{\mathrm{b}}$ & 0.039 & 2.375 \\
\hline & & $\mathrm{B}_{\mathrm{s}}=\mathrm{a}^{*} \mathrm{D}+\mathrm{c}$ & 0.132 & - \\
\hline & & $\mathrm{B}_{\mathrm{b}}=\mathrm{a}^{*} \mathrm{D}+\mathrm{c}$ & 9.116 & - \\
\hline & & $\mathrm{B}_{1}=\mathrm{a}^{*} \mathrm{D}^{\mathrm{b}}$ & 0.422 & 2.370 \\
\hline \multirow[t]{9}{*}{ Secondary forest } & $1.0^{\sim} 5.0$ & $\mathrm{~B}_{\mathrm{r}}=\mathrm{a}^{*} \mathrm{D}^{\mathrm{b}}$ & 0.055 & 1.894 \\
\hline & & $\mathrm{B}_{\mathrm{s}}=\mathrm{a}^{*} \mathrm{D}^{\mathrm{b}}$ & 0.064 & 2.406 \\
\hline & & $\mathrm{B}_{\mathrm{bark}}=\mathrm{a}^{*} \mathrm{D}^{\mathrm{b}}$ & 0.017 & 1.984 \\
\hline & & $\mathrm{B}_{\mathrm{b}}=\mathrm{a}^{*} \mathrm{D}^{\mathrm{b}}$ & 0.025 & 2.149 \\
\hline & & $\mathrm{B}_{\mathrm{l}}=\mathrm{a} * \mathrm{D}^{\mathrm{b}}$ & 0.021 & 1.643 \\
\hline & $>2.0$ & $\mathrm{~B}_{\mathrm{r}}=\mathrm{a}^{*} \mathrm{D}^{2 *} \mathrm{H}^{\mathrm{b}}$ & 0.037 & 0.775 \\
\hline & & $\mathrm{B}_{\mathrm{s}}=\mathrm{a} * \mathrm{D}^{2 *} \mathrm{H}^{\mathrm{b}}$ & 0.017 & 0.805 \\
\hline & & $\mathrm{B}_{\mathrm{b}}=\mathrm{a}^{*} \mathrm{D}^{2 *} \mathrm{H}^{\mathrm{b}}$ & 0.019 & 0.876 \\
\hline & & $\mathrm{B}_{\mathrm{l}}=\mathrm{a}^{*} \mathrm{D}^{2 *} \mathrm{H}^{\mathrm{b}}$ & 0.009 & 0.755 \\
\hline \multirow[t]{8}{*}{ Monsoon rainforest/ monsoon evergreen broad-leaf forest } & $3.0^{\sim} 20.0$ & $\mathrm{~B}_{\mathrm{r}}=\mathrm{a}^{*} \mathrm{D}^{2 *} \mathrm{H}^{2}+\mathrm{b}^{*} \mathrm{D}^{2 *} \mathrm{H}+\mathrm{c}$ & $3 \times 10^{-7}$ & 0.004 \\
\hline & & $\mathrm{W}_{\mathrm{r}}=\mathrm{a}^{*} \mathrm{D}^{2 *} \mathrm{H}^{2}+\mathrm{b}^{*} \mathrm{D}^{2 *} \mathrm{H}+\mathrm{c}$ & $-7 \times 10^{-7}$ & 0.023 \\
\hline & & $\mathrm{W}_{\mathrm{r}}=\mathrm{a}^{*} \mathrm{D}^{2 *} \mathrm{H}^{2}+\mathrm{b}^{*} \mathrm{D}^{2 *} \mathrm{H}+\mathrm{c}$ & $2 \times 10^{-6}$ & -0.002 \\
\hline & & $\mathrm{W}_{\mathrm{l}}=\mathrm{a}^{*} \mathrm{D}^{2 *} \mathrm{H}^{\mathrm{b}}$ & 0.010 & 0.725 \\
\hline & $18.0^{\sim} 90.0$ & $\mathrm{~W}_{\mathrm{r}}=\mathrm{a}^{*} \mathrm{D}^{2 *} \mathrm{H}^{\mathrm{b}}$ & 0.006 & 0.984 \\
\hline & & $\mathrm{W}_{\mathrm{s}}=\mathrm{a}^{*} \mathrm{D}^{2 *} \mathrm{H}^{\mathrm{b}}$ & 0.036 & 0.941 \\
\hline & & $\mathrm{W}_{\mathrm{b}}=\mathrm{a}^{*} \mathrm{D}^{2 *} \mathrm{H}^{\mathrm{b}}$ & 0.206 & 0.632 \\
\hline & & $\mathrm{W}_{\mathrm{l}}=\mathrm{a}^{*} \mathrm{D}^{2 *} \mathrm{H}^{\mathrm{b}}$ & 0.107 & 0.467 \\
\hline
\end{tabular}

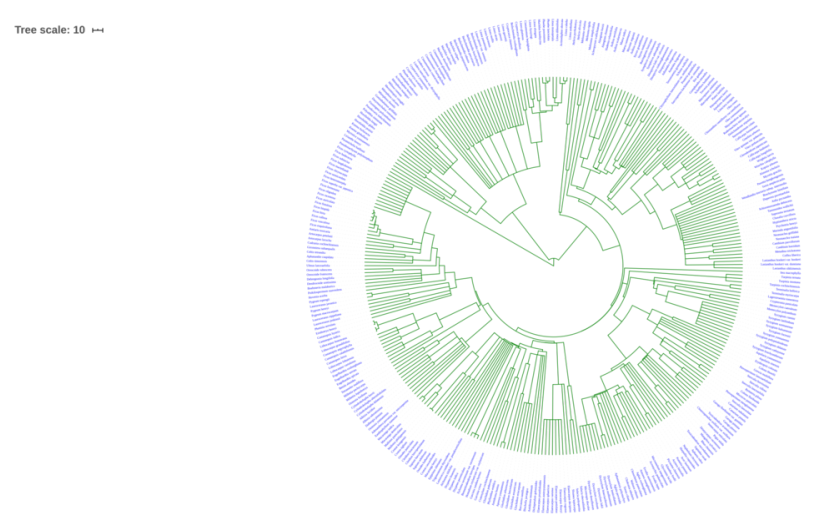

Figure S1. Phylogenetic tree for the 337 species from the 10 plots used in this study 


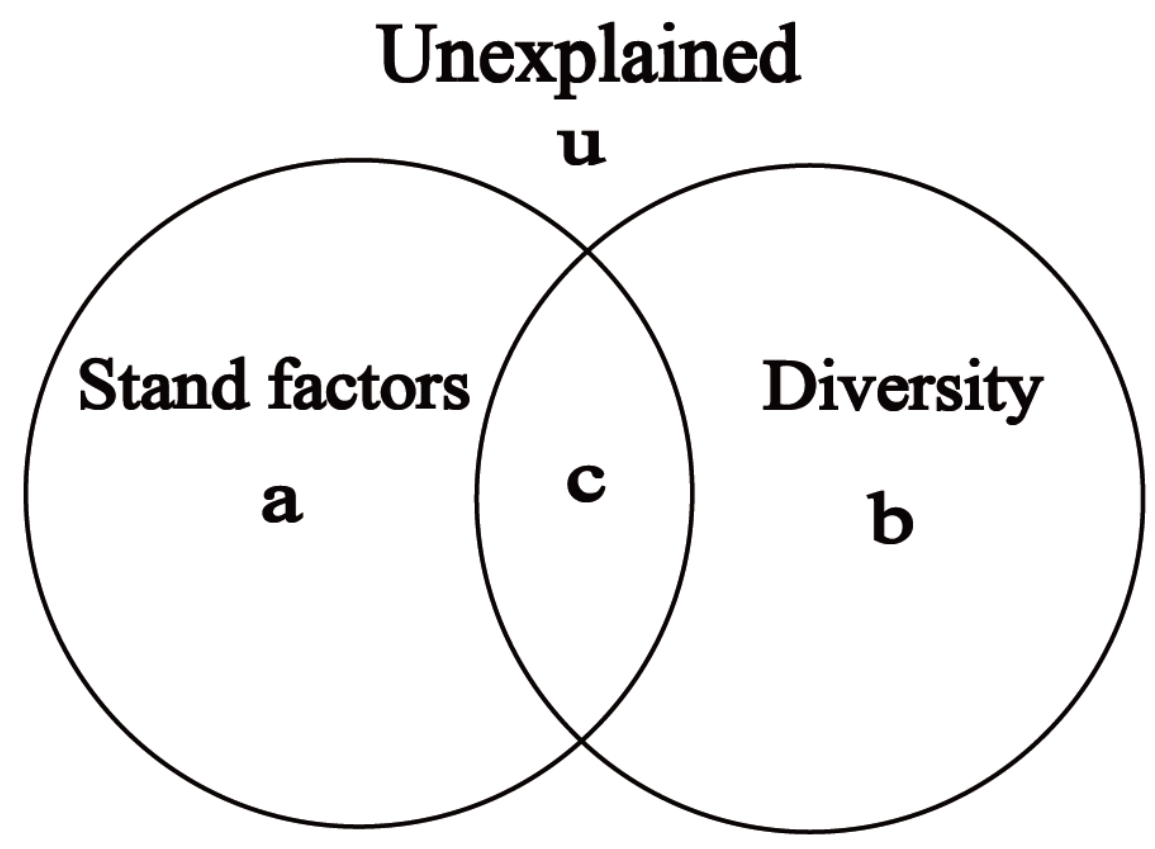

Figure S2. The total effect and independent effect of stand factors and diversity on ecosystem functions and stability. a, b and $\mathrm{c}$ are the independent effect of stand factor, independent effect diversity and join effect of stand factor and diversity, respectively. $a+c, b+c$ are the total effect of stand factor, total effect of diversity, respectively. $\mathrm{u}=1-\mathrm{a}-\mathrm{b}-\mathrm{c}$, the unexplained variation in response variables. 

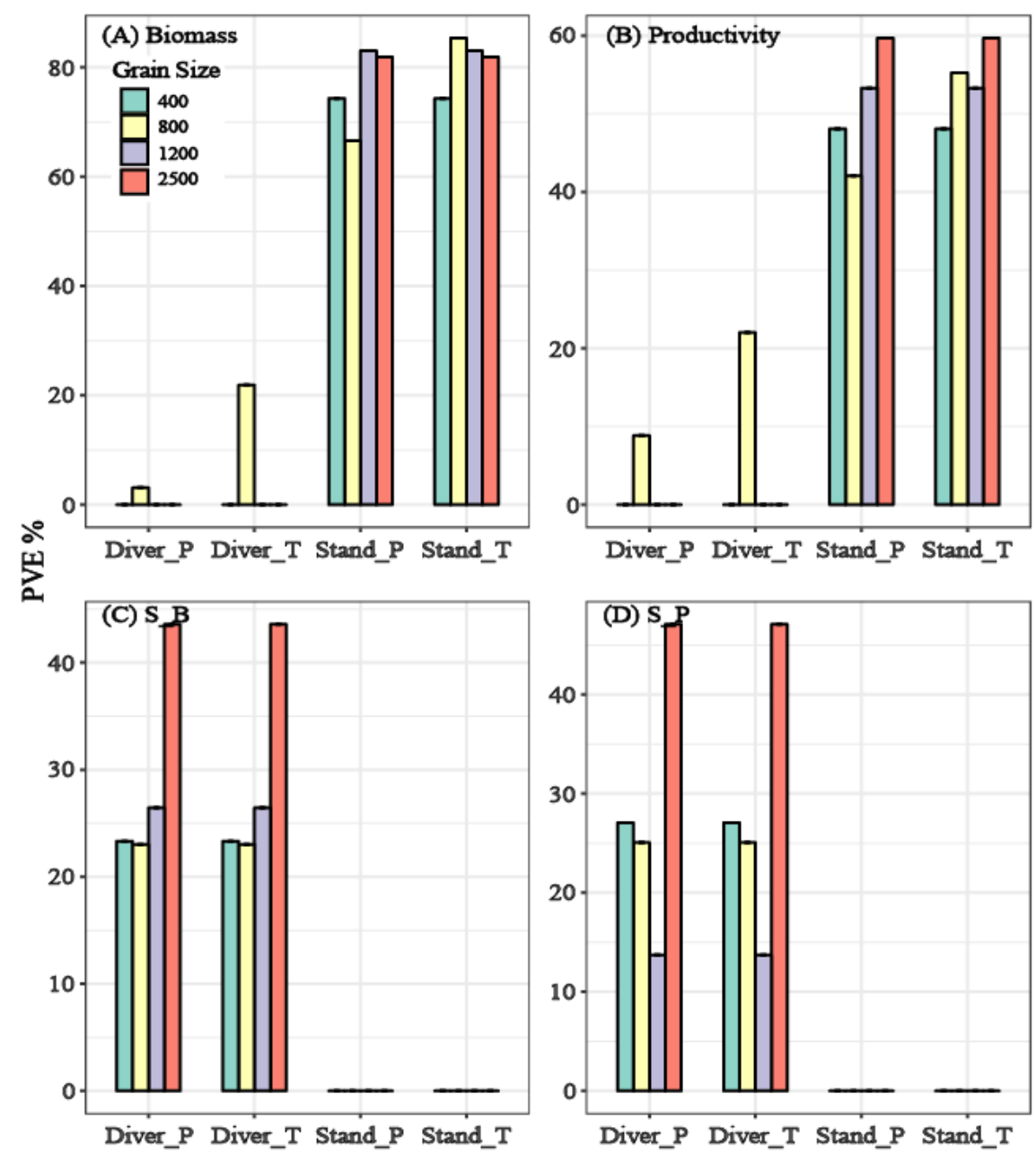

Figure S3. Variation partitioning analysis for the relative importance of stand factors vs. diversity in explaining forest biomass (A), productivity (B) and their stability (C and D, respectively). Different from Fig. 1, results here were based on models in Table 3, which differed markedly in sample size among grain sizes. PVE (\%), percentage of variations explained; Diver_T, Diver_P, Stand_T and Stand_P, the total and pure effect of diversity indices, and the total and pure effect of stand factors, respectively. 